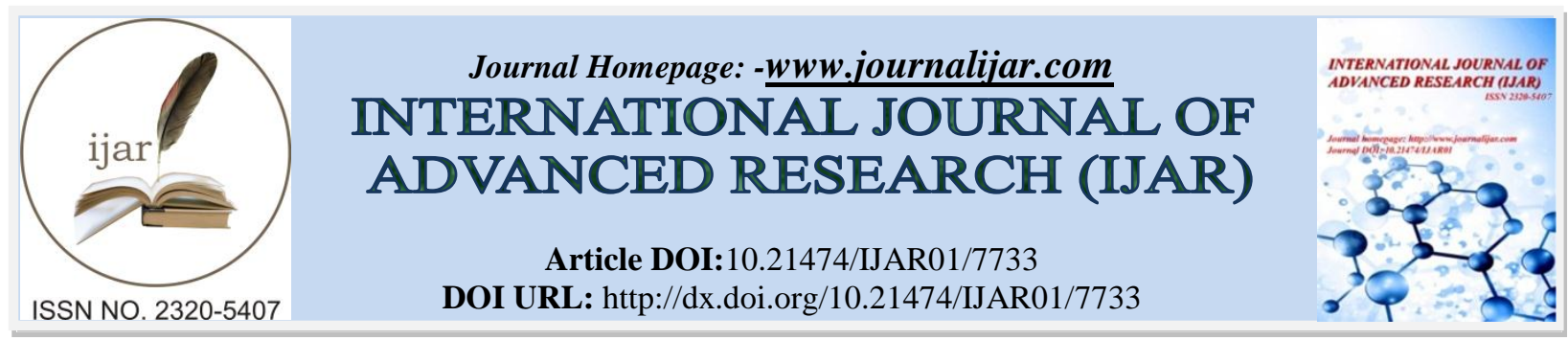

RESEARCH ARTICLE

\title{
TO COMPARE THE LEVELS OF REPRODUCTIVE HORMONES AND TSH IN FEMALES WITH PRIMARY INFERTILITY AND EARLY PREGNANCY LOSS.
}

\author{
Isha Malik, Ashuma Sachdeva,Veena S.Ghalaut, Monica Verma and Monika Dalal. \\ 1. Associate Professor, Department of Biochemistry, Pt BDS PGIMS, Rohtak, Haryana. Pin:124001. \\ 2. Professor, Department of Biochemistry, Pt BDS PGIMS, Rohtak, Haryana. Pin:124001. \\ 3. Senior Professor, Department of Biochemistry, Pt BDS PGIMS, Rohtak, Haryana. Pin:124001. \\ 4. Assistant Professor, Department of Biochemistry, Pt BDS PGIMS, Rohtak, Haryana. Pin:124001. \\ 5. Associate Professor, Department of Obstetrics \& Gynecology, Pt BDS PGIMS, Rohtak, Haryana. Pin:124001.
}

\section{Manuscript Info}

Manuscript History

Received: 22 July 2018

Final Accepted: 28 August 2018

Published: September 2018

\section{Abstract}

\section{Introduction:-}

Infertility is a global reproductive health issue that affects many individuals and couples. It is defined as failure to conceive after one year of regular unprotected intercourse with the same partner. Infertility has been recognized as a public health issue worldwide by the World Health Organization (WHO). In India, the incidence of infertility is 10$15 \%$ as per WHO study. Among the total infertile cases female infertility contributes to $50 \%{ }^{1}$

The inability to procreate is considered as a curse for the couple, impacting on the entire family and even the local community. The psychosocial consequences of childlessness are negative and often severe. ${ }^{2}$ Infertility is of two types: primary and secondary infertility. WHO defines primary infertility as the "Inability to conceive within two years of exposure to pregnancy (i.e. sexually active, non-contracepting, and non-lactating) among women of age group 15 to $49 \mathrm{yr}$ old". Secondary infertility refers to the inability to conceive following a previous pregnancy. Globally, most infertile couples suffer from primary infertility. ${ }^{3}$

Sexually transmitted infections (STIs) are generally considered the leading preventable cause of infertility worldwide, especially in developing countries. STIs cause approximately 70 per cent of all pelvic inflammatory disease (PID) cases, which often result in tubal damage. ${ }^{4}$

The major causes of infertility include ovulatory dysfunction (15\%), tubal and peritoneal pathology (30-40\%) and male factor (30-40\%) and uterine pathology. To some extent the prevalence of each varies with age. Ovulatory dysfunction is more common in younger than old couples, tubal and peritoneal factors have a similar prevalence. ${ }^{5}$

Hormonal imbalances have been associated with female infertility. The increased or decreased levels of FSH, LH and Prolactin (PRL) hormones may cause infertility. FSH and LH hormones belong to glycoprotein family and play an important role in follicular development and production of oestrogen. ${ }^{6}$

Hyperprolactinemia, the presence of abnormally high levels of prolactin in the blood, is the most common endocrine disorder of the hypothalamic-pituitary axis. Clinical and experimental studies have suggested a close relationship between the hypothalamic-pituitary-thyroid axis and the hypothalamic-pituitary-ovarian axis. ${ }^{7}$ Thyroid dysfunction 
can affect fertility in various ways resulting in anovulatory cycles, luteal phase defect, high prolactin levels, and sex hormone imbalances. Therefore, normal thyroid function is necessary for fertility, pregnancy and to sustain a healthy pregnancy, even in the earliest days after conception. Prevalence of hypothyroidism in the reproductive age group is $2-4 \%$ and has been shown to be the cause of infertility and habitual abortion. Hypothyroidism can be easily detected by assessing TSH levels in the blood. A slight increase in TSH levels with normal $\mathrm{T}_{3}$ and $\mathrm{T}_{4}$ indicates subclinical hypothyroidism whereas high TSH levels accompanied by low $\mathrm{T}_{3}$ and $\mathrm{T}_{4}$ levels indicate clinical hypothyroidism. ${ }^{8}$

Many infertile women with hypothyroidism had associated hyperprolactinemia due to increased production of thyrotropin releasing hormone (TRH) in ovulatory dysfunction. It has been recommended that in the presence of raised PRL, the treatment should be first given to correct the hypothyroidism before evaluating other causes of raised PRL. Measurement of TSH and PRL is routinely done as a part of infertility workup. ${ }^{9}$

Although many studies have established the hypothesis that complex hypothalamic-pituitary-thyroid -ovarian interaction is responsible for normal pregnancy outcome, this study was planned to further prove that any disturbance in any of the pathways can cause infertility and habitual abortions.

\section{Material and Method:-}

We included total of 90 women from Gynecology and Obstetrics Department,PGIMS, Rohtak. Out of which 30 were with normal fertility as controls between the age of 18-40 years (Group -I), 30 women were with primary infertilty between the age of 18-40 years (Group-II) and rest 30 were of early pregnancy loss (EPL) between age of 18-40 years (Group-III). We checked for the inclusion and exclusion criteria.

Inclusion Criteria: For controls, women between age of 18-40 years with uneventful pregnancy and for Early pregnancy loss we included females with intrauterine pregnancy with either an empty gestational sac or a gestational sac containing an embryo or fetus without fetal heart activity within the first 10- 12 weeks of gestation.

Exclusion Criteria: Chronic illness like TB and anatomical pathology.

The partners of all these patients eventually were proven healthy after ruling out male factor infertility. Blood was collected on $3^{\text {rd }}$ day of cycle and was analysed for routine investigations. Also LH, FSH, Prolactin and TSH were measured by chemiluiniscent technique using standard kits provided by Siemens.

\section{Results:-}

1. In the present study the mean age in all the three groups was comparable. Also the routine invastigations like Hemoglobin, TLC, DLC,ESR, blood sugar,blood urea and serum creatinine were with in the reference range and comparable in all the groups.

2. The mean level of FSH among Group I was $6.25 \pm 1.54 \mathrm{mIU} / \mathrm{L}$ while among

3. Group II was $6.41 \pm 2.23 \mathrm{mIU} / \mathrm{L}$ and FSH level among Group III was $8.01 \pm 2.48 \mathrm{mIU} / \mathrm{L}(\mathrm{Table}-1)$ Statistical analysis showed that difference in the mean values in the Group I and Group III was non significant ( $p>0.05)$, While difference in the mean values in the Group I and Group II was found to be significant $(\mathrm{p}<0.05)$.

4. The mean level of $\mathrm{LH}$ among control group was $5.24 \pm 1.63 \mathrm{mIU} / \mathrm{L}$ while among

5. Group II was13.12 $\pm 10.6 \mathrm{mIU} / \mathrm{L}$ and among Group III was15.5 $\pm 15.7 \mathrm{mIU} / \mathrm{L}(\mathrm{Table}-2)$. Statistical analysis showed that difference in the mean values in the Group I and Group III was significant $(\mathrm{p}<0.05)$ and the difference in the mean values in the Group I and Group II was also significant $(\mathrm{p}<0.05)$.

6. The mean level of Prolactin among control group was $15.38 \pm 1.68 \mathrm{ng} / \mathrm{ml}$ while among

7. Group II was $13.12 \pm 10.6 \mathrm{ng} / \mathrm{ml}$ and Prolactin level among Group III was $48.52 \pm 14 \mathrm{ng} / \mathrm{mL}(\mathrm{Table}-3)$. Statistical analysis showed that difference in the mean values in the Group I and Group III was significant $(\mathrm{p}<0.05)$ and the difference in the mean values in the Group I and Group II was also significant $(\mathrm{p}<0.05)$.

8. The mean level of TSH among Group I was 3.09 $\pm 1.16 \mathrm{mIU} / \mathrm{L}$ while among

9. Group II was9.04 $\pm 10.2 \mathrm{mIU} / \mathrm{L}$ and among Group III was 9.38 $\pm 9.52 \mathrm{mIU} / \mathrm{L}($ Table-4). Statistical analysis showed that difference in the mean values in the Group I and Group III was significant $(\mathrm{p}<0.05)$ and the difference in the mean values in the Group I and Group II was also found to be significant $(\mathrm{p}<0.05)$.

10. Discussion:

11. Infertility is a state of failure to conceive due to multiple factors. The cause of repeated abortions with having no successful pregnancy is also included under infertility. The reproduction is controlled by complex interaction between steroid hormones, gonadotrophins, hypothalamic - pituitry- ovarian axis. A disruption in any of these 
can result in infertility and pregnancy loss. ${ }^{10}$ Steroid hormone production as well as follicular development is under the control of gonadotrophins. Any alteration in the balance of control mechanisms governing follicle growth indirectly affects oocyte function subsequently. Impaired fertilization and defective embryo growth are caused by altered gonadotrophin levels. ${ }^{11}$

12. The purpose of this study was to establish the fact that endocrine abnormalities detected by hormone assays are associated with infertility and pregnancy loss.

13. Circulating FSH levels begin to rise during the late luteal phase and decline during the midfollicular phase as a result of the modulatory effects of circulating E2, inhibin, and possibly other gonadal hormones on the hypothalamic-pituitary axis. The FSH levels are used to predict ovarian reserve, reproductive potential and as prognostic indicator of pregnancy rate. Basal FSH levels are used by various infertility centres as a mean to predict pregnancy rates in IVF.Most of the authors have used $10 \mathrm{mlU} / \mathrm{ml}$ as cut off value for an elevated FSH. ${ }^{12}$ Esposito evaluated that decline in pregnancy rate was associated with elevated FSH levels. He also confirmed that day 3 FSH has high specificity and poor sensitivity. ${ }^{13}$ Williams et al established the fact that basal FSH concentration is the favoured marker for predicting pregnancy rates and pregnancy outcomes. They took the cut off point at $12 \mathrm{mlU} / \mathrm{ml}^{14}$

14. In the present study day $3 \mathrm{FSH}$ were measured in the infertile patients. The mean FSH levels were $6.25 \pm 1.54$ in the control group and $6.41 \pm 2.23$ in the infertile patients, which was found to be statiscally non significant. However the range of day $3 \mathrm{FSH}$ is below $10 \mathrm{mlU} / \mathrm{ml}$ in infertile patients which is consistent with cut off values of other studies.

15. There is increased risk of pregnancy loss due to genetic abnormalities which is associated with advanced age and decreased ovarian reserve. Although ovarian reserve decreases with age but many other factors which directly impact ovaries also play an important role in early pregnancy loss. ${ }^{6}$ Levi et al compared reproductive outcome between the females regarding ovarian reserve.Abnormal ovarian reserve was taken when basal FSH levels were above 14.2 IU/L. They concluded that women with diminished ovarian reserve have high rate of early pregnancy loss. In the present study $3 \mathrm{FSH}$ were measured in the patients with a previous history of recurrent abortions. ${ }^{15}$

16. The mean FSH levels were $6.25 \pm 1.54$ in the control group and $8.01 \pm 2.48$ in the EPL group which was found to be significant and comparable with most of the studies. Our data suggests the role of basal FSH levels in assessing the ovarian reserve and reproductive potential of female.

17. LH is associated with mid cycle surge and important for initiating the mechanisms leading to follicle rupture. Also exposure of ovaries to high LH concentration during follicular growth is harmful for developing oocyte as LH penetrates the follicle and causes premature oocyte maturation which leads to poor fertilization and increased chances of abortion. ${ }^{16}$ Homburg et al studied role of LH in infertile women . Their results indicated that high follicular LH levels have a deleterious effect on the conception rate. ${ }^{17}$ Regan et al studied basal LH levels in nulliparous and multiparous women and concluded that measurement of LH is a very powerful predictive test for pregnancy and abortion rates. ${ }^{18}$

18. In the present study basal LH levels were measured in infertile patients to evaluate the role of LH in pregnancy rates. The mean levels of LH were $5.24 \pm 1.602$ and $13.12 \pm 10.62$ in the control and infertile patients respectively.Results were found to be statistically significant as compared to controls.

19. Regan et al demonstrated a strong relationship between raised serum LH levels and pregnancy loss, whereas Nordo et al showed no such relationship. ${ }^{18,19}$ In the present study basal day 3 LH levels were measured in patients with a previous history of recurrent early pregnancy loss. The mean values of LH were $15.5 \pm 15.01$ and $5.24 \pm 1.602$ in the EPL and control group respectively which were statistically significant and in accordance with other studies. Our data strongly suggests the role of LH in follicular growth and confirms that high LH levels reduce oocyte capacity to fertilize and develop normally.

20. Prolactin also called lactogenic hormone is a hormone produced by the pituitary gland. It has role in puberty, breast development, pregnancy and lactation. Elevated levels of prolactin interfere with the action of gonadotrophins at the ovarian level ultimately leading to infertility. Hyperprolactinemia often presenting with oligomenorrhoea/amenorrhoea and anovulation along with milder alterations of gonadal functions. ${ }^{20}$ Samal et al studied association between hyperprolactinemia in female infertility. They concluded that higher prolactin levels were found in the infertile patients. ${ }^{21}$ Avasthi et al also showed that the incidence of hyperprolactinemia in female infertility was quite high which was in accordance with other studies. ${ }^{22}$

21. In the present study basal follicular prolactin levels were measured on day 3. Mean value of prolactin was $23.46 \pm 14.62$ in infertile patients and $15.38 \pm 1.68$ in the control group which was significant. Our study concludes that any alteration in the hypothalamic pituitary axis contributing to high prolactin levels may lead to infertility. 
22. Bussen et al studied the serum concentration of prolactin in patients with history of recurrent abortions and found that prolactin levels were significantly raised. ${ }^{23}$ In our study mean levels of prolactin was $48.52 \pm 14.09$ and 15.38 \pm 1.68 the EPL and control group which was significant. We submit that there is potential role of prolactin in abortions. Thus all the women with infertility or early pregnancy loss should be screened for prolactin levels.

23. Hypothyroidism is associated with a broad range of reproductive disorders ranging from infertility to recurrent abortions. This can be explained by the presence of thyroid hormone receptors in human oocytes. TSH also affects fertility by altering the metabolism of oestrogen and leads to abnormal feed back at pituitary. Females with hypothyroidism are having high prevalence of anovulation.Also patients with autoimmune diseases are having $\mathrm{T}$ cells in blood and thyroid gland which may cause pregnancy loss. ${ }^{24}$ Arozoki et al studied hypothyroidism among infertile women and concluded that there is a significant relation of TSH with infertility. ${ }^{25}$ Avasthi et al studied the incidence of hyperprolactinemia and hypothyroidism among infertile women and found that TSH levels were significantly increased in the study group. ${ }^{22}$

24. In the present study TSH levels were measured in infertile patients to know the significance of subclinical hypothyroidism as infertility factor. The TSH levels were 9.04 \pm 9.22 in the study group and $3.09 \pm 1.16$ in the control group . They were found to be significantly elevated on comparison which is in consistence with other studies.

25. Ablovich et al showed that women with primary hypothyroidism have high abortion rate. ${ }^{26}$ Gurbuz et al evaluated the potential role of endocrine imbalance in females with unexplained early pregnancy loss. Their study observed no difference in thyroid hormone levels in the study and control group. ${ }^{11}$ In the present study we estimated the TSH levels in patients with bad obstetrical history to see the relation of abnormal TSH levels and abortion rate. The mean value was $11.08 \pm 11.02$ in the study group and $3.09 \pm 1.16$ in the control group which was significantly higher and comparable with most of other studies.

26. As the role of thyroid hormones in abortion rate is slight controversial, for the infertility work up screening of thyroid functions is strongly recommended. Chernova et al evaluated the origin of hyperprolactinemia in patients with primary hypothyroidism and concluded that both the disorders may be associated due to disturbed dopaminergic regulation. ${ }^{27}$ Avasthi et al also studied the correlation between TSH and prolactin and found it positive. $^{22}$ In the present study coefficient of correlation between TSH and prolactin in the infertility group was found to be 0.087 . Correlation was positive.Also the coefficient of correlation between TSH and prolactin and EPL group was calculated andfound to be positive i.e.0.264, which is in accordance with the previous studies.

27. Conclusion: From the present study we conclude that women with infertility and abortions have subtle disturbances in the hypothalamic pituitary axis that may include ovarian and thyroid dysfunction as compared with women with normal fertility pattern. Our findings support the hypothesis that endocrinal disturbances are associated with infertility and pregnancy loss. Our study did not evaluate subsequent cycle or samples on day to day basis, hence our observations may represent a transient abnormality but it is reasonable to assume that a change in any of the endocrine factors may lead to the change in the hormonal milieu of the body and hence may play a role in the etiology of infertility and abortions.

Table I:-Comparison of FSH in three Groups

\begin{tabular}{|c|c|c|c|}
\hline Group & No. of cases & Range(mlU/ml) & Mean \pm SD \\
\hline Control (I) & 30 & $4.4-9.1$ & $6.25 \pm 1.54$ \\
\hline Infertility (II) & 30 & $2.2-11.1$ & $6.41 \pm 2.23 *$ \\
\hline EPL (III) & 30 & $3.28-12.78$ & $8.01 \pm 2.48 * *$ \\
\hline
\end{tabular}

Table 2:-Comparison of LH in three Groups

\begin{tabular}{|l|l|l|l|}
\hline Group & No. of cases & Range(mlU/ml) & Mean \pm SD \\
\hline Control (I) & 30 & $2.9-8.2$ & $5.24 \pm 1.602$ \\
\hline Infertility (II) & 30 & $2.03-46.13$ & $13.12 \pm 10.62 *$ \\
\hline EPL (III) & 30 & $2.07-45.8$ & $15.5 \pm 15.01 * *$ \\
\hline \hline
\end{tabular}


$* p<0.05$ (S) when compared with control

** $p<0.05$ (S) when compared with control

Table3:-Comparison of prolactin in three Groups

\begin{tabular}{|l|l|l|l|}
\hline Group & No. of cases & Range $(\mathrm{ng} / \mathrm{ml})$ & Mean \pm SD \\
\hline Control (I) & 30 & $11.36-17.5$ & $15.38 \pm 1.68$ \\
\hline Infertility (II) & 30 & $8.03-62.12$ & $23.46 \pm 14.62^{*}$ \\
\hline EPL (III) & 30 & $13.4-155.3$ & $48.52 \pm 14.09^{* *}$ \\
\hline
\end{tabular}

${ }^{*} \mathrm{p}<0.05$ (S) when compared with control

$* * \mathrm{p}<0.05$ (S) when compared with control

Table4:-Comparison of TSH in three Groups

\begin{tabular}{|l|l|l|l|}
\hline Group & No. of cases & Range $(\mathrm{mlU} / \mathrm{ml})$ & Mean \pm SD \\
\hline Control & 30 & $1.54-5.2$ & $3.09 \pm 1.16$ \\
\hline Infertility & 30 & $2.7-41.2$ & $9.04 \pm 9.22^{*}$ \\
\hline EPL & 30 & $2.06-50.8$ & $11.08 \pm 11.02 * *$ \\
\hline
\end{tabular}

$* \mathrm{p}<0.05$ (S) when compared with control

** $p<0.05$ (S) when compared with control

\section{References:-}

1. BMascarenhas MN, Flaxman SR, Boerma T, Vanderpoel S, Stevens GA. National, regional, and global trends in infertility prevalence since 1990: a systematic analysis of 277 health surveys. PLoS medicine. 2012 Dec 18;9(12):e1001356.

2. Rouchou B. Consequences of infertility in developing countries. Perspectives in public health. 2013 May;133(3):174.

3. Adamson PC, Krupp K, Freeman AH, Klausner JD, Reingold AL, Madhivanan P. Prevalence \& correlates of primary infertility among young women in Mysore, India. The Indian journal of medical research. 2011 Oct;134(4):440.

4. Van Balen F, Gerrits T. Quality of infertility care in poor-resource areas and the introduction of new reproductive technologies. Human Reproduction. 2001 Feb 1;16(2):215-9.

5. Smith C, Grimm M, Schwegel M. Treatment of infertility in women. Journal of the American Pharmacists Association. 2012 Jul 1;52(4):e27-42.

6. Simoni M, Gromoll J, Nieschlag E. The follicle-stimulating hormone receptor: biochemistry, molecular biology, physiology, and pathophysiology. Endocrine reviews. 1997 Dec 1;18(6):739-73.

7. Bauer J, Isojärvi JI, Herzog AG, Reuber M, Polson D, Taubøll E et al. Reproductive dysfunction in women with epilepsy: recommendations for evaluation and management. Journal of Neurology, Neurosurgery \& Psychiatry. 2002 Aug 1;73(2):121-5.

8. Verma I, Sood R, Juneja S, Kaur S. Prevalence of hypothyroidism in infertile women and evaluation of response of treatment for hypothyroidism on infertility. International journal of applied and basic medical research. 2012 Jan;2(1):17.

9. Dittrich R, Beckmann MW, Oppelt PG, Hoffmann I, Lotz L, Kuwert T et al. Thyroid hormone receptors and reproduction. Journal of reproductive immunology. 2011 Jun 1;90(1):58-66.

10. Gharib SD, Wierman ME, Shupnik MA, Chin WW. Molecular biology of pituitaty gonadotrophins EndocrRev 1990;11:177.

11. Gurbuz B, Yalti S, Ficicioglu C,Ozden S,Yildirim G, Sayar C: Basal hormone levels in women with recuerrent pregnancy loss.Gynecol Endocrinol 2003;17(4): 37-9.

12. Barnhart K,Osherof J: Follicle stimulating hormone as a predictor of fertility. Curr Opin Obstet Gynecol1998; :227-32.

13. Esposito MA, Coutifaris C,Barnhart KT. A moderately elevated day 3 FSH concentration predictive value in younger women. Human Reproduction 2002;17(1): 118-23.

14. Williams C, GiamnopoulosT, Sheriff EA. Investigation on infertility with emphasis on laboratory testing. J Clin Pathol 2003;56:261-7.

15. Levi AJ, Raynault MF,Bergh PA,Drews MR, MillerBT,Scott RT.Reproductive outcome in patients with diminished ovarian reserve. Fertility and Stertility2001;76(4):666-9.

16. JaffeSH, Jewelewics R. The basic infertility investigations. Fertil stertil1991;56:599-613. 
17. Homburg R,Armer NA,Eshel A,Adams J,Jacobs HS. Influence of serum luteinizing hormone concentrations on ovulation ,conception and early pregnancy loss in polycystic ovarian syndrome.Br Med J1988;17:123-34.

18. Regan L,Owen EJ,JacobsHS. Hypersecretion of luteinizing hormone ,infertility and miscarriage. The Lancet,336:1141-46.

19. Nordo LG, Rai R,Backos M,El-Gaddal-S,Regan L. High serum luteinizing hormone and testosterone concentrations do not predict pregnancy outcome in women with recurrent miscarriage. Fertil stertil 2002;5677(2):38-52.

20. Kalsum A,Jalali S.Role of hyperprolactinemia in infertility. Pakistan J Med Res2002;41(3):1-8.

21. Samal S, Aggarwal P,Gupta U. Evaluation of sympomology in hyperprolactinemic infertile women.J Obstet Gynecol Ind 2002;52(2):76-80.

22. Avasthi K, Kaur J,Gupta S,Narang PA. Hyperprolactinemia and its correlation with hypothyroidism in infertile women.J Obstet Gynecol Ind 2006;56(1):68-71.

23. Bussen S, Sutterlin M, Steck T. Endocrine abnormalities duringthe follicular phase in women with recurrent spontaneous abortions.Hum Reprod 1999;14(1):18-20.

24. Chen YT,Khoo DH.Thyroid diseases in pregnancy.Ann Acad Med Singapoe2002;31(3):296-302.

25. Arozoki M,Jokimaa AM, Juuti A, Koshkinen P,Irjala K,Antilla L. Hypothyroidism among infertile women in Finland.Gynecol Endocrinol 2000; 14:127-31.

26. Abalovich M, Gutierrezs S, Alacaraz G, Maccallini G, Garcia A, Lavalle O. Overt And subclinical hypothyroidism complicating pregnancy. Marry Ann Liebert, Inc.-Thyroid 2002; 12(1):63-68

27. Chernova TO, Kolesnikova GS, Mudretsova SV, Serpukhovitin Slu, Goncharov NP, Gereasimov GA. Prolactin and TSH response in functional tests in patients with primary hypothyroidism in a context of hyperprolactinemia. Probl Endokrinol (mosk) 1994; 40(5):16-8. 